\title{
Martensitic Transformation Under Compression of a Plasma Processed Polycrystalline Shape Memory CuAlNi Alloy
}

Fábio de Oliveira Braga ${ }^{a, b *}$, Anatoliy Nikolaevich Matlakhov ${ }^{c}$, Lioudmila Aleksandrovna Matlakhova ${ }^{c}$,

\author{
Sergio Neves Monteiro ${ }^{a}$, Carlos José de Araújo ${ }^{d}$ \\ anstituto Militar de Engenharia - IME, Department of Materials Science, Praça General Tibúrcio, 80, \\ Praia Vermelha, Urca, RJ, CEP 22290-270, Urca, Rio de Janeiro, RJ, Brazil. \\ ${ }^{b}$ Serviço Nacional de Aprendizagem Industrial do Estado do Rio de Janeiro (SENAI-RJ), SENAI \\ Rio Faculty, Rua Mariz e Barros, 678, CEP 20270-003, Tijuca, Rio de Janeiro, RJ, Brazil. \\ ${ }^{c}$ Universidade Estadual do Norte Fuminense - UENF, Advanced Materials Laboratory, \\ Campos dos Goytacazes, RJ, Brazil. \\ ${ }^{d}$ Universidade Federal de Campina Grande - UFCG, Multidisciplinary Laboratory of Materials \\ and Active Structures, Campina Grande, PB, Brazil.
}

Received: June 24, 2016; Revised: July 24, 2017; Accepted: August 02, 2017

Shape memory alloys (SMA) are attracting considerable attention owing to possible applications from biomedical to aerospace. In particular, CuAlNi alloys present significant advantages associated with low cost, easy processing and superior thermo-electric conductivity over other SMAs such as the NiTi alloys. Characterization of some properties and structural changes caused by martensitic transformation are still open to investigation. The present work evaluated these characteristics in an as-cast plasma processed shape memory $\mathrm{Cu}-14 \mathrm{wt} . \% \mathrm{Al} 4 \mathrm{wt} . \% \mathrm{Ni}$, which was compression tested until fracture. Experimental results showed that an as-cast ingot presents not only chemical and phase homogeneity, but also microstructures composed of grains with martensitic morphology. Martensites $\beta_{1}^{\prime}$ and $\gamma_{1}^{\prime}$, as well as intermediary martensitic R and high temperature $\beta_{1}$ were identified by X-ray diffraction tests. It was found that the compressive deformation does not interfere in the phase composition and martensite morphology. However, compression changes the volumetric fractions and crystallographic orientation of the martensites. The mechanical behavior is characterized by an apparent elastic response until the fracture. The fractured surface exhibits brittle aspect like "river patterns" and evidence of intergranular rupture.

Keywords: CuAlNi, Polycrystalline alloy, Compressive behavior, Mechanical properties.

\section{Introduction}

Shape memory alloys of the copper-aluminum-nickel (CuAlNi) system have, since decades, attracted considerable attention owing to a pseudoelastic behavior caused by reversible martensitic transformation $(\mathrm{RMT})^{1-49}$. The composition interval for its occurrence was found to be: aluminum with 13.0 to $15 \mathrm{wt} . \%$ and nickel with 3.0 to 4.5 wt. $^{16,21,25,43}$. This behavior, which likewise could be interpreted as pseudoplastic ${ }^{45}$, has long been found in other alloy systems such as Ti-Ni, $\mathrm{Cu}-\mathrm{Zn}$ and $\mathrm{Cu}-\mathrm{Zn}-\mathrm{Al}^{50-53}$. The RMT is associated with fundamental effects currently used in many practical applications ranging from biomedical implants to aerospace devices ${ }^{54-59}$. Among the RMT related effects, stands the alloy ability to remember its original shape prior to an imposed pseudoplastic deformation. This is today well known as the shape memory effect (SME) displayed by shape memory alloys (SMAs) like the CuAINi presently studied. The basic motivation behind this investigation was the fact that a CuAlNi alloy, as SMA, is recognized to have significant advantages over the more commonly used Ti-Ni (Nitinol) alloys. In terms of processing, CuAlNi alloys display less melting and casting difficulty, which allows for more precise composition control $37,43,45,56$. Moreover, they have higher stiffness and superior thermal and electrical conductivities $^{37}$. Despite the lack of biocompatibility, which is a relevant biomedical advantage of Nitinol, CuAlNi components are not only less expensive but also easy to machine, and do not oxidize as readily as titanium based components. Consequently, they represent a viable SMA alternative for non-medical actuator devices ${ }^{45}$. 
Different $\mathrm{CuAlNi}$ compositions have been investigated as $\mathrm{SMA}^{1-49}$, but a common point is the RMT, which involves the basic martensitic transformation, either thermal-only or stress-assisted.

$$
\beta_{1} \longleftrightarrow \beta_{1}^{\prime}+\gamma_{1}^{\prime}
$$

The higher temperature metastable cubic $\beta_{1}$, which is an ordered type $\mathrm{DO}_{3}\left(\mathrm{BiF}_{3}\right)$ phase $e^{3,26}$, may undergo a reversible transformation involving two distinct martensites: orthorhombic $\beta_{1}^{\prime}$, an ordered type $18 \mathrm{R}\left(\mathrm{Cu}_{3} \mathrm{Al}\right)$ phase ${ }^{3}$, and orthorhombic $\gamma_{1}^{\prime}$, an ordered type $2 \mathrm{H}(\mathrm{Cu} 3 \mathrm{Ti})$ phase ${ }^{3}$. Another rhombohedral, ordered type $\mathrm{Al}_{7} \mathrm{Cu}_{4} \mathrm{Ni}$ metastable phase has also been reported for certain $\mathrm{CuAlNi}$ alloys ${ }^{39,44}$. This so called intermediate or $\mathrm{R}$ martensite is coherent with $\beta_{1}$ as well as with the martensites $\beta_{1}^{\prime}$ and $\gamma_{1}^{\prime}{ }_{1}^{44}$.

Several works have been dedicated to polycrystalline CuAlNi SMAs ${ }^{2,4-8,12-15,34,41,43,45,47,49}$, yet, most fundamental works are devoted to single crystals. However, practical applications might require polycrystalline SMA components ${ }^{57-59}$. In these cases, depending on the alloy composition, processing condition and initial grain size as well as thermal and/or mechanical treatment, different RMT parameters related to microstructure and properties are obtained ${ }^{41,43,45,47-49}$. In particular, Sari and Kirindi ${ }^{41}$ investigated the microstructure and compression properties of a $\mathrm{Cu}-11.92$ wt.\%Al-3.78 wt. $\% \mathrm{Ni}$ alloy produced by arc-melting. Specimens were homogenized $\left(650\right.$ and $\left.950{ }^{\circ} \mathrm{C}\right)$ followed by quench in ice water. Compression tests were performed up to $9 \%$ of maximum strain. They observed intergranular fracture and occurrence of grain boundary precipitation. For Sari and Kirindi ${ }^{41}$, as well others ${ }^{14,60-62}$, intergranular fracture indicates that a significant strain is developed adjacent to the grain boundaries. Although the amount of Al in Sari and Kirindi work ${ }^{41}$ is slightly lower than the typical range (13 to 15 wt. $\% A 1)^{43}$ for RMT, their results will serve as basic reference for the present investigation. Therefore, the objective of the present work was to investigate, for the first time, the transformation parameters, microstructural changes and properties of an as-cast polycrystalline 82.11 wt $\% \mathrm{Cu}-13.95$ wt $\% \mathrm{Al}-3.94$ wt $\% \mathrm{Ni}(\mathrm{Cu}-14 \% \mathrm{Al}-4 \% \mathrm{Ni}$ for short) alloy. In special, this alloy was processed by plasma melting in a Brazilian laboratory and metastable martensitic transformation was induced by compression in as-cast specimens without previous heat treatment. It will be shown that the as-cast condition of the present work has significant advantages over the thermal-treated alloy investigated by Sari and Kirindi ${ }^{41}$.

\section{Materials and Methods}

Pro-analysis copper, aluminum and nickel powders were used in the production of the polycrystalline $\mathrm{Cu}-14 \mathrm{Al}-4 \mathrm{Ni}$ alloy.
Fabrication process was carried out in the Multidisciplinary Laboratory of Materials and Active Structures (LaMMEA), of the Federal University of Campina Grande (UFCG), Brazil, through the plasma melting technique followed by injection molding. For compression tests, the as-cast ingot ( $25 \mathrm{~mm} \mathrm{x}$ $25 \mathrm{~mm} \times 5 \mathrm{~mm}$ ) was sectioned, using a mechanical cutter, into prismatic-shaped samples with dimensions $4 \mathrm{~mm} \times 4$ $\mathrm{mm} \times 8 \mathrm{~mm}$, as shown in Figure 1 .

Compression tests were conducted up to fracture, in a model 5582 Instron machine operating at a cross-head speed of $0.1 \mathrm{~mm} / \mathrm{min}$. Three samples were tested for a limited statistical analysis. In order to reveal the microstructure, the alloy was subjected to conventional metallographic preparation by sandpaper and diamond paper paste polishing followed by chemical etching with a $\mathrm{FeCl}_{3}+\mathrm{HCl}$ water solution. The microstructural observation was carried out by means of: (a) optical microscopy (OM), using an Olympus-BX41M and a Neophot-32 microscope; (b) scanning electron microscopy (SEM), in a SSX-550 Shimadzu equipment; and (c) atomic force microscopy (AFM), in a model NanoScope 3D Bruker equipment. The quantification of the structural components was performed by micrographs and image characterization in a Scion Image-4032 analyzer.

The chemical composition and the distribution of elements in the alloy were studied by means of: (a) energy dispersive spectroscopy (EDS), with atomic number (Z), absorption (A) and fluorescence (F) correction (ZAF); and atomic emission spectroscopy (AES) with argon gas inductively coupled plasma (ICP).

The identification of phases was performed by $\mathrm{Cu}-\mathrm{K}_{\alpha}$ X-ray diffraction (XRD), in a model XRD-7000 Shimadzu diffractometer, using the database of the JCPDS program version 2006, for peaks identification.

The bulk density $\left(\rho_{\mathrm{a}}\right)$ of the alloy was measured by means of the Archimedes hydrostatic weighing method in distilled water. The experimental density (Eq. 2) was compared with the theoretical one $\left(\rho_{t}\right)$, estimated from the nominal composition of the alloy (Eq. 3 ).

$$
\begin{gathered}
\rho_{a}=\frac{G_{a i r}\left(\rho_{w t}-\rho_{a i r}\right)}{G_{a i r}-G_{w t}}+\rho_{w t} \\
\rho_{t}=\sum_{i=1}^{k} \rho_{i} C_{i}
\end{gathered}
$$

Where $\mathrm{G}_{\text {air }}$ and $\mathrm{G}_{\mathrm{wt}}$ are the weights of the sample measured in air and in water; $\rho_{\text {air }}$ and $\rho_{\mathrm{wt}}$ the densities of air and water, respectively; $\rho_{\mathrm{i}}$ and $\mathrm{C}_{\mathrm{i}}$ the density and the mass fraction of the chemical elements in the alloy.

The Vickers microhardness of the alloy was measured by means of a MHP-100 device coupled to the Neophot-32 microscope, under a constant load of $30 \mathrm{~g}$. The microhardness values ( $\mathrm{HV}$ in $\mathrm{kgf} / \mathrm{mm}^{2}$ ) were calculated by the following expression: 

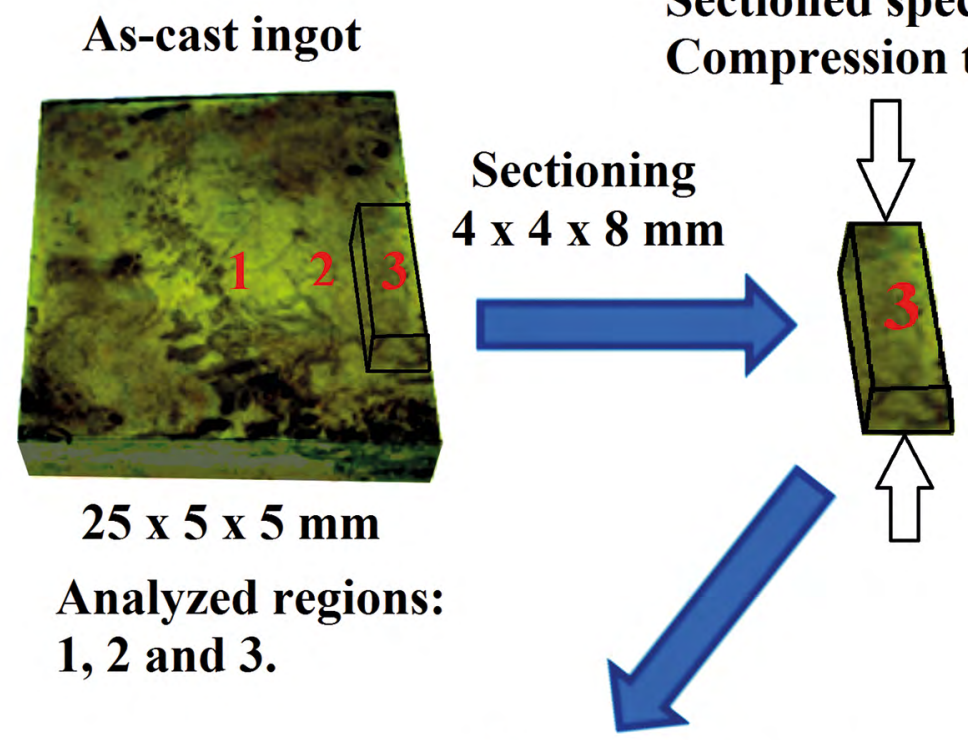

Fractured specimen

Analyzed face Contains region 3

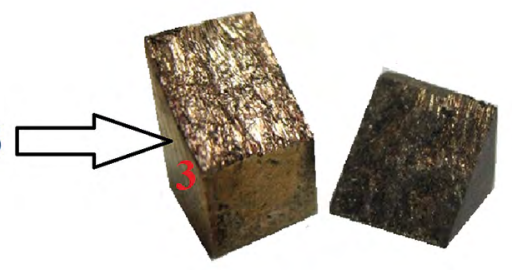

Figure 1. Representative flow chart of the specimen extraction from the as-cast ingot and regions analyzed.

$$
H V=1854 \frac{P}{d^{2}}
$$

Where $\mathrm{P}$ is the applied load ( $\mathrm{g}$ ) and $\mathrm{d}$ is the diagonal of indentation $(\mu \mathrm{m})$.

The electrical resistivity of the alloy $r(\mu \Omega \mathrm{cm})$ was measured by the four-point probe method, using a Tectronix-OS2520G DC power source and an Agilent-34420A multimeter.

$$
r=2 \pi s \frac{U}{I}
$$

Where $\mathrm{U}$ is the electric potential $(\mu \mathrm{V})$; I the electrical current $(\mathrm{mA})$; s the distance between the terminals $(\mathrm{mm})$.

\section{Experimental Results}

Table 1 shows the chemical composition of the alloy, obtained by EDS-ZAF and ICP-AES. Figure $2 \mathrm{~b}$ shows the $\mathrm{X}$-ray emission spectra in the whole area and in two points of the SEM image in Figure 2a.

Figure 3 shows the $\mathrm{Cu}, \mathrm{Al}$ and $\mathrm{Ni}$ characteristic X-ray maps as well as the profiles of X-ray emission of these elements along a line.
Table 1. Chemical composition of the as-cast alloy measured through two methods.

\begin{tabular}{ccccc}
\hline \multicolumn{2}{c}{ Method } & Al (wt.\%) & Ni (wt.\%) & $\mathbf{C u ( w t . \% )}$ \\
\hline \multirow{2}{*}{ EDS-ZAF } & In area & 13.40 & 4.65 & \\
& In point 1 & 14.02 & 3.55 & \\
& In point 2 & 14.08 & 3.67 & Balance \\
ICP-AES & Dissolution & 14.30 & 3.90 & \\
\multicolumn{2}{c}{ Average } & 13.95 & 3.94 & \\
\hline
\end{tabular}

Table 2 presents the theoretical density of the alloy, estimated from its nominal composition (NC), Eq. 3, and the bulk densities ( $\rho$ in $\mathrm{g} / \mathrm{cm}^{3}$ ) obtained both in the as-cast state and fractured conditions, measured by the hydrostatic weighing (HW), Eq. 2.

The micrographs shown in Figure 4 were obtained by OM and SEM, and illustrate the lamellar martensitic morphology existing within the grains. The secondary electron images, Figure $4 \mathrm{~d}$ and $4 \mathrm{e}$, contain also topographic information (secondary electrons) and Figure 4f, compositional information.

Figure 5 shows AFM results of the as-cast alloy, both as $2 \mathrm{D}$ in Figure $5 \mathrm{a}$ and $5 \mathrm{~d}$, and $3 \mathrm{D}$ images in Figure $5 \mathrm{c}$ and $5 \mathrm{f}$, as well as surface roughness profiles, Figure $5 \mathrm{~d}$ and $5 \mathrm{f}$, where micro-pores can be visualized. 


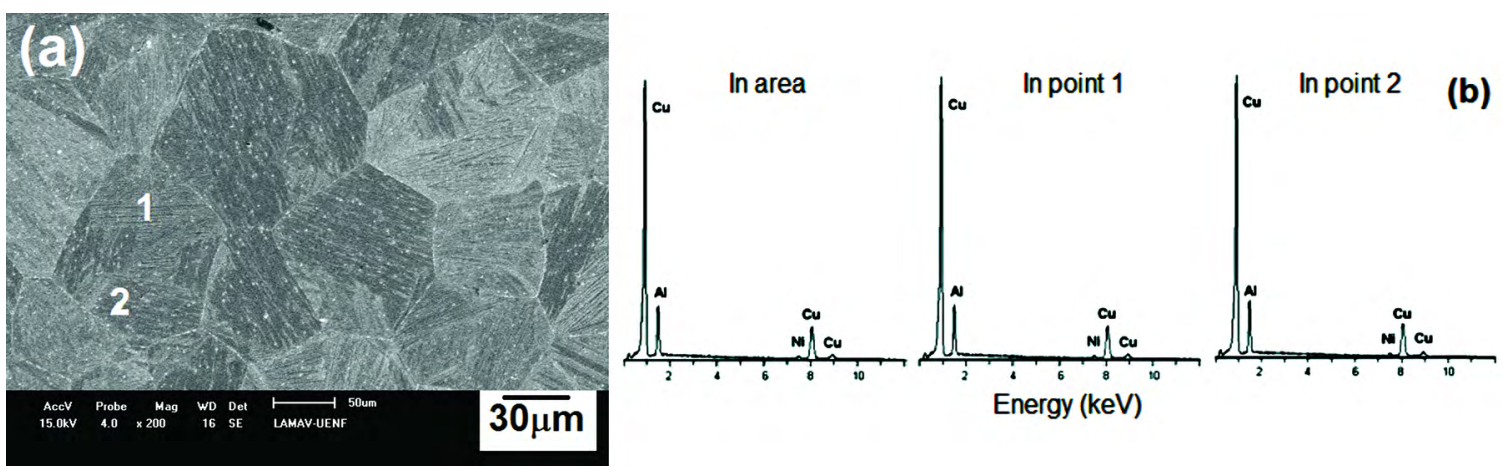

Figure 2. X-ray microanalysis (EDS-ZAF) in a scanned area and in two points within the same grain: (a) SEM image and (b) X-ray emission spectra in area and in the two points.

Figure 6a presents a typical compressive stress-strain curve up to fracture of the alloy. A relatively extensive pseudoelastic behavior, to almost $10 \%$ strain should be noticed in this curve. The strength $\left(\sigma_{\max }\right)$ and the deformation at maximum stress $\left(\varepsilon_{\max }\right)$ as well as the modulus of elasticity (E) and modulus of resilience $\left(\mathrm{U}_{\mathrm{r}}\right)$ were evaluated, and are listed in Table 3. Figure $6 \mathrm{~b}$ shows the general aspect of the fractured sample, with a relatively flat surface of rupture associated with a brittle behavior.

SEM micrographs of the fracture surface are presented in the Figure 7.

Figure 8 shows the OM and SEM micrographs of the fractured alloy. The lamellar martensitic morphology existing within the grains and the topographic contrast of the surface should be noticed in this figure.

Figure 9 shows the grain size distribution of the as-cast and fractured alloy. To investigate the homogeneity of the grain sizes, three regions indicated in Figure 1 had their grain sizes measured and corresponding histograms shown in Figure $9 \mathrm{a}, 9 \mathrm{~b}$ and $9 \mathrm{c}$. Table 4 presents the minimum $\left(\mathrm{d}_{\min }\right)$, maximum $\left(\mathrm{d}_{\max }\right)$ and average $(\mathrm{d})$ grain size.

The results of Vickers microhardness and electrical resistivity measurements in the as-cast and fractured alloy can be found in Tables 5 and 6 . Once more, the measurements were performed in the three different regions indicated in Figure 1 , in order to investigate the alloy structural homogeneity.

The phase compositions of the as-cast and fractured alloy are illustrated by the XRD patterns shown in Figure 10. They indicate the presence of the $\beta 1_{1}$ and $\gamma_{1}^{\prime}$ martensitic phases. Moreover, two other phases are revealed: the high temperature cubic $\beta_{1}$ and the intermediary R. As can be noticed, only metastable phases were found and there is no sign of the stable phases, $\alpha, \beta, \gamma_{2}$ and $\mathrm{NiAl}$, reported in the literature ${ }^{25}$.

\section{Discussion}

The investigation of the chemical composition by EDS-ZAF and ICP-AES (Table 1) showed that the concentrations of $\mathrm{Al}$ and $\mathrm{Ni}, 13.95$ and $3.94 \mathrm{wt} . \%$, respectively, are within the typical range, which is well known to show RMT ${ }^{16,21,25,43}$ and thus present SME by quenching from the austenitic state.
Considering Figure 2 and 3, the main goal was to verify if the as-cast alloy was chemically homogeneous. Thus, it was chosen to begin the chemical microanalysis within a single grain, at the two points of Figure 2a, and then compare this result to the average composition obtained in the total area of the same image. The spectra were quite similar (Figure 2b), and this indicates the absence of segregation within each grain and in the alloy as a whole. Figure 3 is an expansion of the previous chemical analysis. X-ray maps of a large area (Figure 3a), and the composition profiles along a line that crosses a grain boundary (Figure $3 b$ ) were obtained. None of these results showed signs of chemical segregation in the alloy, and then it can be considered chemically homogeneous.

The theoretical density, estimated from the nominal composition (NC), refers to the maximum density that this alloy may exhibit $\left(8.08 \mathrm{~g} / \mathrm{cm}^{3}\right)$, which is useful as a reference to the values obtained through the hydrostatic weighing in Table 2. As expected, the bulk density of the alloy presents a lower value $\left(7.15 \mathrm{~g} / \mathrm{cm}^{3}\right)$, probably due to porosity and other defects. After the deformation, the bulk density remains the same, considering the standard deviation of $0.05 \mathrm{~g} / \mathrm{cm}^{3}$. Both density values lies within the range $\left(7.1-7.2 \mathrm{~g} / \mathrm{cm}^{3}\right)$ reported in the literature for these alloys ${ }^{56}$.

The OM images of the as-cast alloy, shown in Figure $4 \mathrm{a}, 4 \mathrm{~b}$ e $4 \mathrm{c}$, reveal that the microstructure is composed of grains with typical martensitic morphology. Indeed, the martensite exhibits classical shapes associated with plates and thin lamellae, both parallel and crossed, with different orientations within the grains. The SEM micrographs in Figure $4 \mathrm{~d}$ and $4 \mathrm{e}$ show, besides the martensitic morphology, the possibility of porosity in the alloy. The pores had their approximate depth size measured in Figure $5 \mathrm{e}$ as $350 \mathrm{~nm}$. The nature of this porosity is uncertain, and they could be either real porosity of the alloy, inherent to the fabrication process, or precipitates that were removed by being anodic relative to the matrix during the chemical etch. Since the phases identified in the X-ray diffraction analysis are thought to be coherent to the martensitic major constituents ${ }^{44}$, and no stable phases were detected, the first hypothesis might be considered more probable. However, this is still opened 

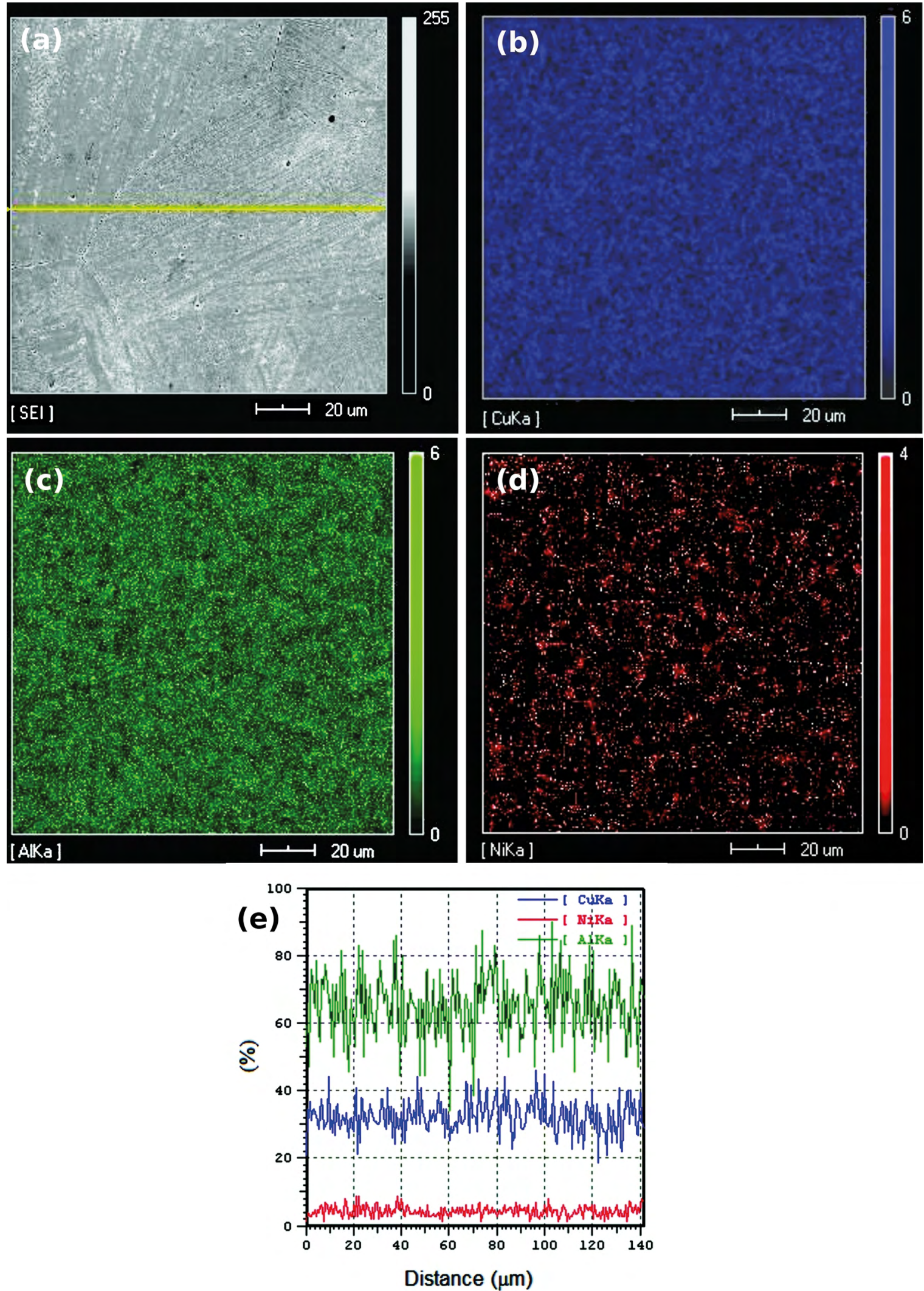

Figure 3. X-ray microanalysis: (a) SEM image; Characteristic X-ray maps for (b) $\mathrm{Cu}$; (c) $\mathrm{Al}$ and (d) Ni; (e) X-ray emission profiles of the elements along a line. 
Table 2. Theoretical density of the alloy calculated through the nominal composition (NC) and average bulk density evaluated through hydrostatic weighing (HW).

\begin{tabular}{ccc}
\hline Alloy & Method & $\boldsymbol{\rho}\left(\mathbf{g} / \mathbf{c m}^{\mathbf{3}}\right)$ \\
\hline \multirow{2}{*}{ As-cast } & NC & 8.079 \\
& HW & $7.15 \pm 0.02$ \\
Fractured & HW & $7.22 \pm 0.05$ \\
\hline
\end{tabular}
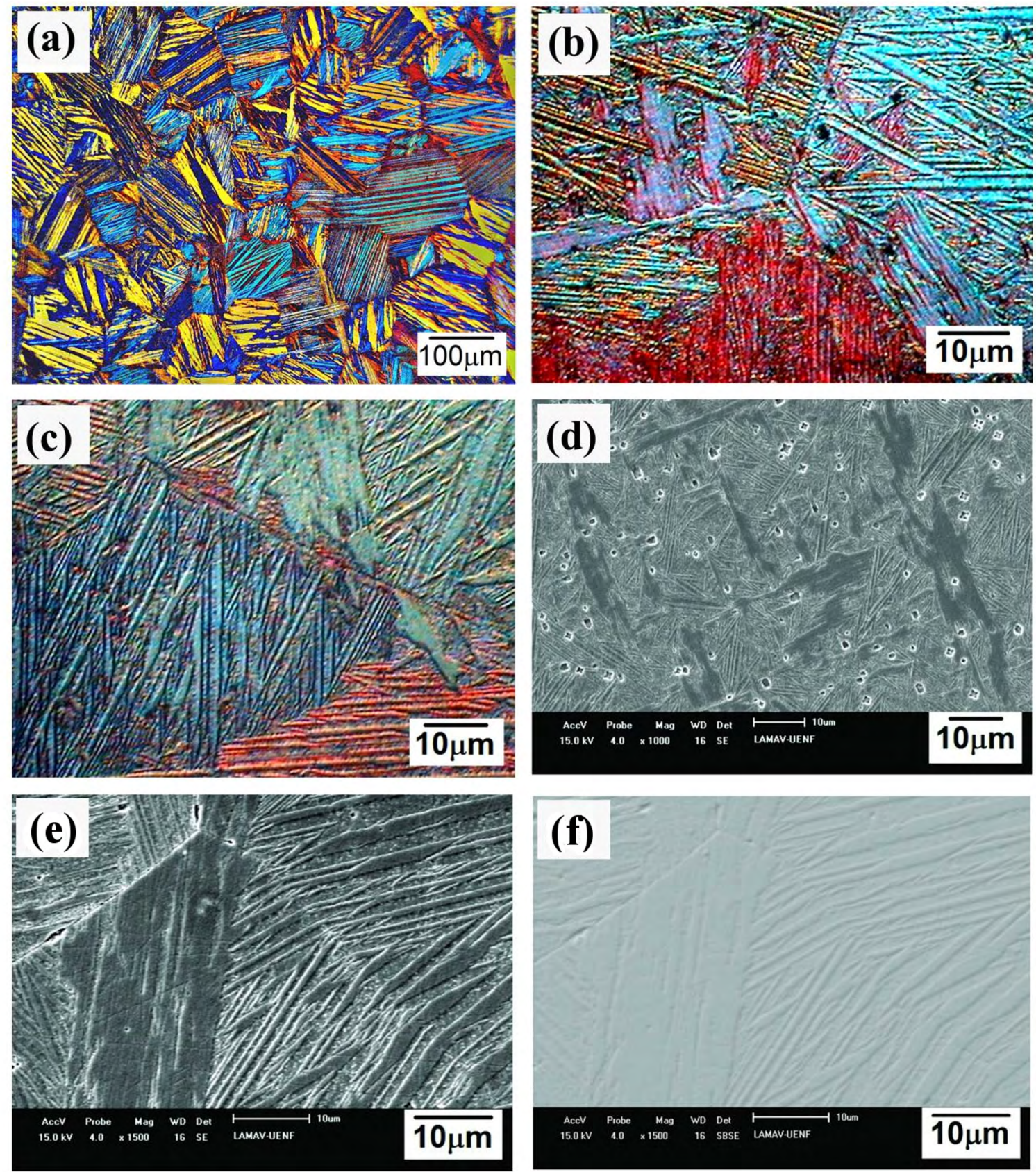

Figure 4. Microstructure of the as-cast alloy: (a) OM, without chemical etching, polarized light, 100x; (b,c) OM, differential interference contrast, 1.000x; (d,e) SEM, secondary electrons, 1.000x and 1.500x; and (f) SEM, backscattered electrons, 1.500x. 
$401.06 \mathrm{~nm}$

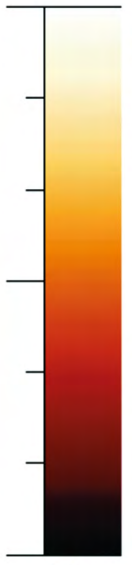

$0.00 \mathrm{~nm}$
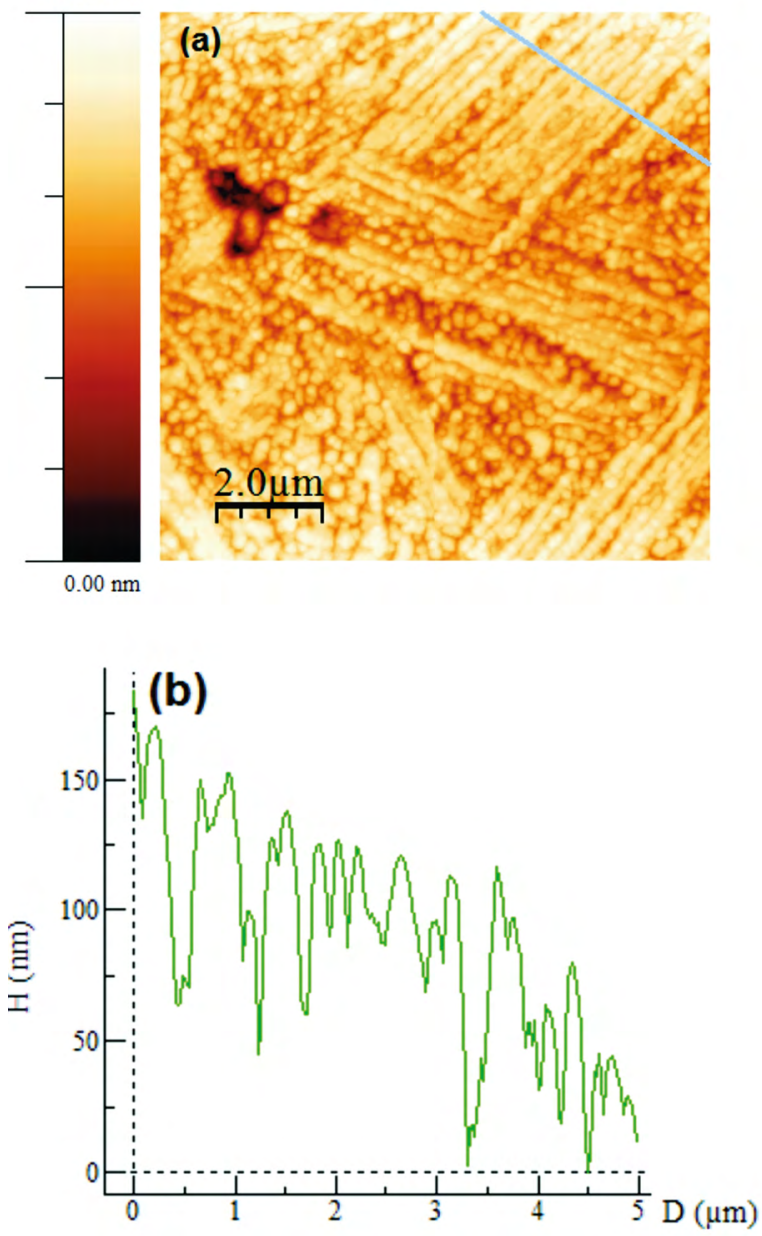

$642.00 \mathrm{~nm}$
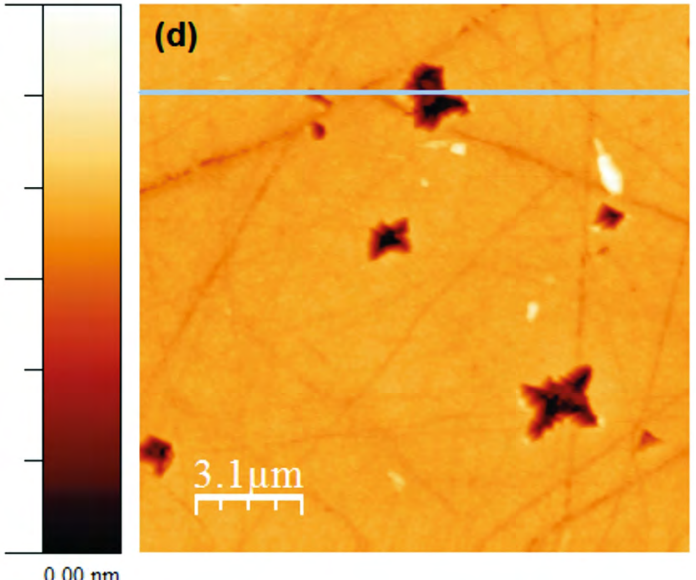

(e)

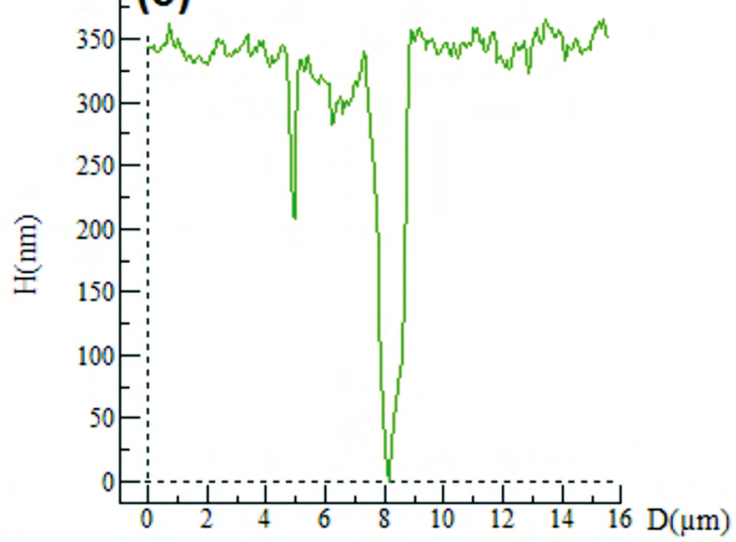

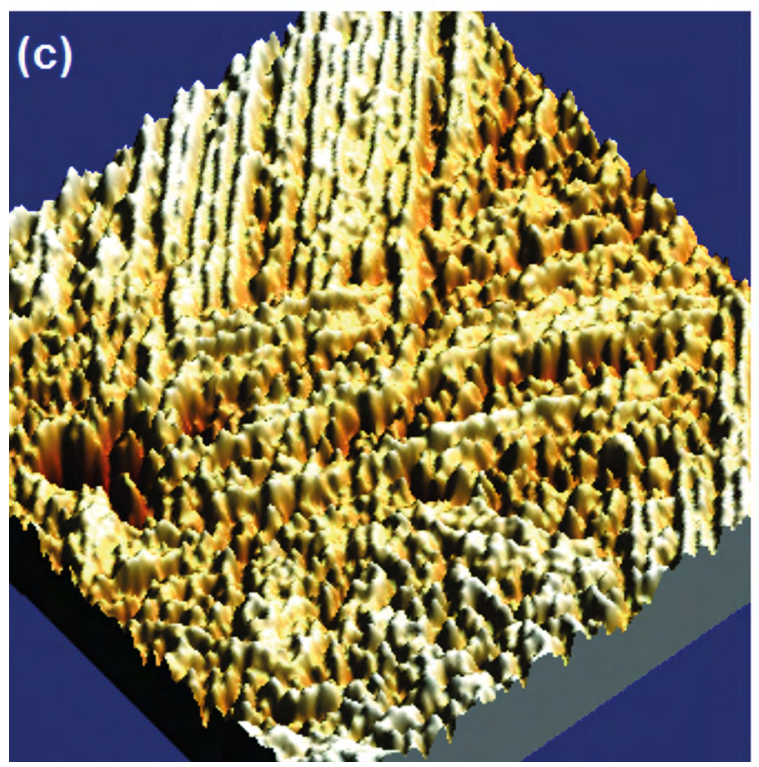

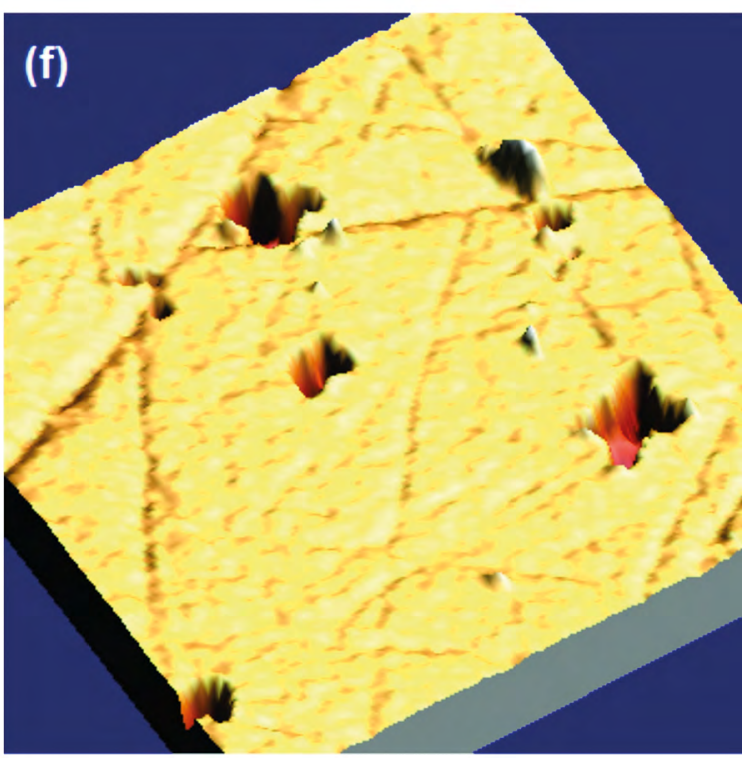

Figure 5. Topographic aspect of the as-cast alloy evaluated by AFM: (a) microstructure, chemically etched; (b-c) roughness profile along the line and 3D reconstruction of 5(a); (d) microstructure, with a light chemical etch; (e-f) roughness profile along the line and 3D reconstruction of $5(\mathrm{~d})$. 

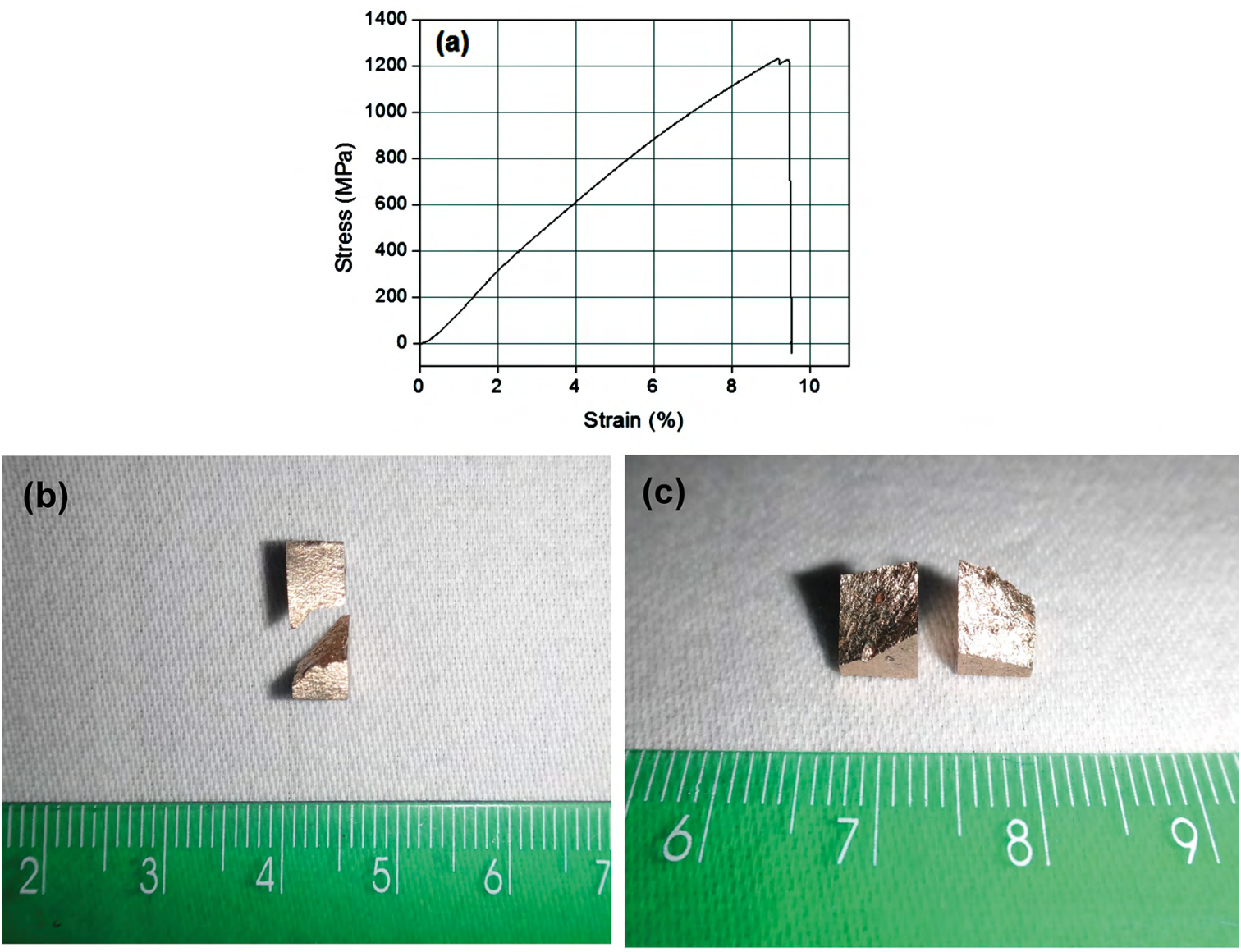

Figure 6. Compression test: (a) Stress-strain curve and (b-c) general aspect of the fractured sample.

Table 3. Average mechanical properties of the alloy.

\begin{tabular}{ccccc}
\hline & $\boldsymbol{\sigma}_{\max }(\mathbf{M P a})$ & $\boldsymbol{\varepsilon}_{\max }(\boldsymbol{\%})$ & $\mathbf{E}(\mathbf{G P a})$ & $\mathbf{U}_{\mathbf{r}}\left(\mathbf{M J} / \mathbf{m}^{\mathbf{3}}\right)$ \\
\hline Property & $1260 \pm 42$ & $10.9 \pm 2.4$ & $11.8 \pm 2.2$ & $68.8 \pm 17.3$ \\
\hline
\end{tabular}

An important point to be discussed regarding the homogeneous microstructure of the present as-cast $\mathrm{CuAlNi}$ alloy is the absence of grain boundary precipitates. This might contribute to prevent intergranular fracture. In the case of thermally treated CuAlNi alloy investigated by Sari and $\mathrm{Kinindi}^{41}$, precipitation was indicated to occur during the initial annealing treatment. In particular, annealing at $650^{\circ} \mathrm{C}^{63,64}$ caused precipitates that restricts the mobility of the martensite variants and twin interfaces. Failure with completely intergranular fracture was attributed to the presence of brittle precipitate phases at the grain boundaries ${ }^{14,63}$.

The mechanical behavior of the alloy, illustrated by the stress-strain curve in Figure 6, was characterized, in general, by an apparent pseudoelastic response until fracture, associated with high strength, $1260 \pm 42 \mathrm{MPa}$, and moderate deformation $(10.8 \pm 2.4 \%)$. The elastic modulus and the modulus of resilience were calculated as $11.8 \pm 2.2 \mathrm{GPa}$ and $68.8 \pm 17.3 \mathrm{MJ} / \mathrm{m}^{3}$, respectively. Mukunthan and Brown ${ }^{65}$ reported in a grain refined $\mathrm{CuAlNi}$ alloy similar fracture stress (1200 MPa) and strain (10\%), achieved by sequential hot rolling operations. Their samples, however, were tested in tension ${ }^{25,65}$. This exceptional mechanical behavior, earlier reported by Mukunthan and Brown ${ }^{65}$ in tension and here found in compression, is not typical for alloys with SME, which usually presents a "pseudo-yield" plateau ${ }^{18,30,38,50}$ and low values of maximum stress ${ }^{6,22,41,49}$. In other works ${ }^{6,22,49,66}$ on CuAINi polycrystalline SMAs, the ultimate strength was usually less than $500 \mathrm{MPa}$, especially due to the fragility of the grain boundaries, which makes them susceptible to intergranular stress cracking ${ }^{6,25,41}$. Several causes have been reported for this intergranular fracture phenomenon, such as high elastic anisotropy leading to stress concentration at the grain boundaries, large grain sizes $(\sim 1 \mathrm{~mm})$ and formation of stress induced martensites along grain boundaries upon quenching ${ }^{25}$. In the present work, the fractured surface of the alloy in Figure 7 exhibits some characteristics of brittle fracture, associated with mixing evidence of intergranular with transgranular, Figure 7a and 7b, and "river patterns", Figure7c. The sample was fractured along shear planes, Figure $6 \mathrm{~b}$ and $6 \mathrm{c}$, at almost 45 degrees from the direction of the applied load. The fracture aspects in Figure 7 are the same observed by other authors, where the effect of 


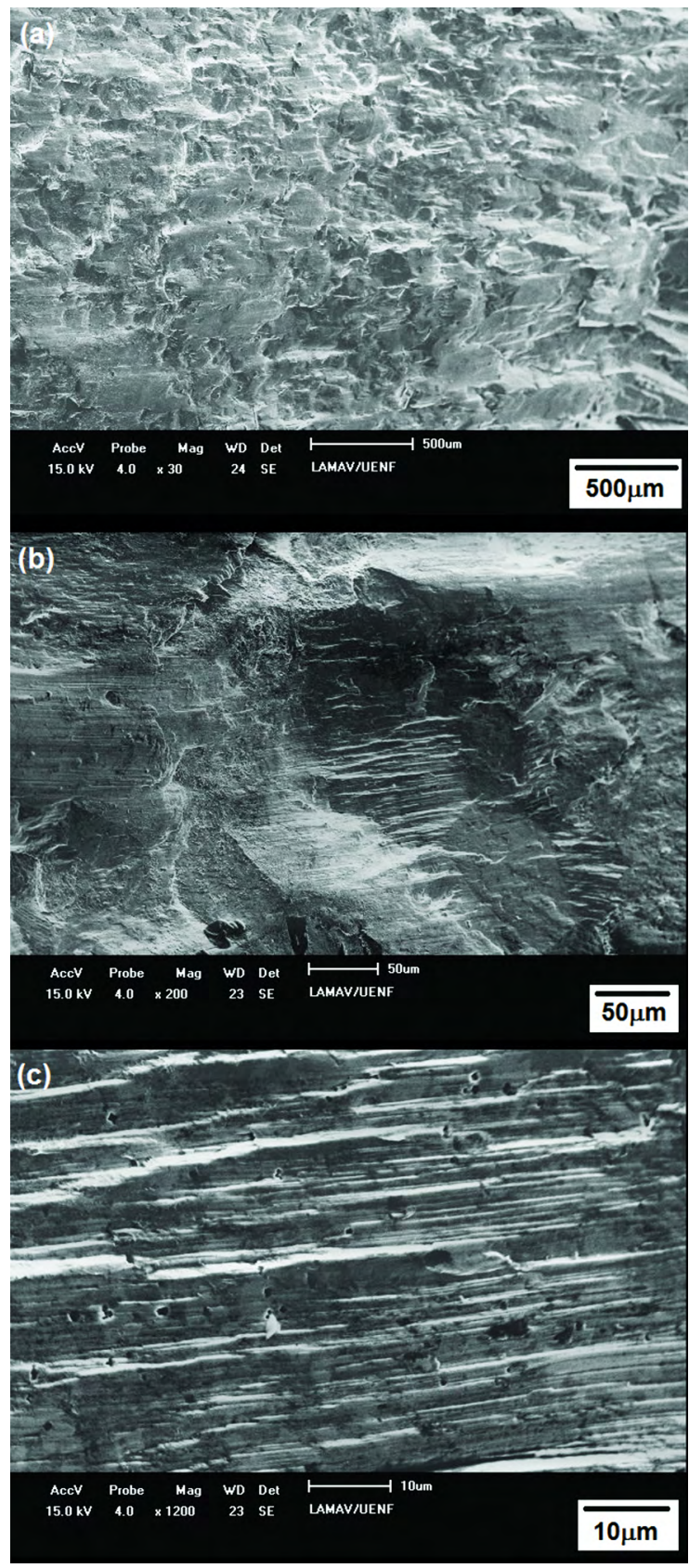

Figure 7. SEM images of the fractured surface: (a) mixing intergranular and transgranular; (b) typical transgranular and (c) river patterns.

deformation on the microstructure of both polycrystalline ${ }^{41}$ and monocrystalline ${ }^{42} \mathrm{Cu}-\mathrm{Al}-\mathrm{Ni}$ with comparable compositions were reported.

Sari and Kirindi ${ }^{41}$ studied the effect of compressive deformation of several heat treated, polycrystalline CuAlNi. They obtained less than $900 \mathrm{MPa}$ as maximum strength, despite the thermal treatments. The present results indicate that the plasma melting technique together with injection molding can be a satisfactory route to produce higher strength polycrystalline CuAlNi alloys, to be used under compressive loads. Besides that, it was not necessary any further heat or mechanical treatment to obtain superior mechanical properties.

The large pseudoelastic region, about $10 \%$, in the stress-strain curve in Figure 6a comes from the martensite elasticity that prevails in the structure combined with crystallographic reorientation of the martensitic phases within the grains. This is caused by the applied compression. As the reorientation of martensites may not be completed, some martensitic variants might change due to the relatively higher stresses $^{41,50}$. The deformation until fracture does not change the martensitic morphology and does not significantly modify the size of the martensite plates and lamellae, as shown in Figure $8 \mathrm{a}, 8 \mathrm{~b}$ and $8 \mathrm{c}$.

According to the grain measurements presented in Figure 9 and Table 4, the as-cast alloy displays a large variation in grain sizes, from $58 \mu \mathrm{m}$ to $154 \mu \mathrm{m}$, at all analyzed regions. All grains revealed an approximately Gaussian distribution profile of sizes, and average sizes very close to each other $(100 \mu \mathrm{m}, 110 \mu \mathrm{m}$ and $120 \mu \mathrm{m})$. After the test, the grain sizes became smaller, Figure 9 and Table 4 , due to the axial compressive deformation. These smaller grain sizes vary from a minimum of $15 \mu \mathrm{m}$ up to a maximum of $85 \mu \mathrm{m}$, with an average size of $46 \mu \mathrm{m}$. The typical range of grain sizes $25-100 \mu \mathrm{m}$ was previously reported for the CuAlNi alloys ${ }^{56}$. Despite that, Sari and Kirindi ${ }^{41}$ mentioned large grain sizes of about 600 to $900 \mu \mathrm{m}$, observed for the thermally treated $\mathrm{Cu}-11.92 \mathrm{wt} . \% \mathrm{Al}-4 \mathrm{wt} . \% \mathrm{Ni}$. This seems to be one of the reasons for their limited strength, when compared to the present work.

The microhardness values measured in three distinct regions, Figure 1, of the as-cast alloy, shown in Table 5 $(310 \pm 10,320 \pm 20$ and $330 \pm 13 \mathrm{HV}$ ), are relatively high and quite similar. These are indication of the presence of the intermetallic phases and also the homogeneity of the ingot in terms of phase composition. Since Figure 6a shows a small eventual yield point discontinuity at $1200 \mathrm{MPa}$, one might expect slight increase $(384 \pm 81 \mathrm{HV})$ in the microhardness. This change could also be expected due to the observed $\beta_{1} \rightarrow R$ phase transformation, since $\mathrm{R}$ is a coherent intermetallic precipitate ${ }^{44}$. The dispersion of microhardness data is high due to, probably, the distinct strain accommodation within the different grains, as can be seen in Figure $8 \mathrm{a}, 8 \mathrm{~b}$ and $8 \mathrm{c}$. In those figures, highly strained darker grains are observed while some other grains show a smaller amount of the characteristic deformation bands. However, the high standard deviation makes it difficult to confirm the phenomena, being necessary to observe also the electrical resistivity results, which are more sensitive. The electrical resistivity increased from $11.68 \pm 0.13$ to $19.90 \pm 0.96 \mu \Omega \mathrm{cm}$, and this is a clear indication of the increasing amount of structural defects such as martensitic twins and dislocations ${ }^{41}$. The smaller grain size observed for the section analyzed might be responsible for the higher electrical resistivity too, but not the higher microhardness, since this property was measured within the 

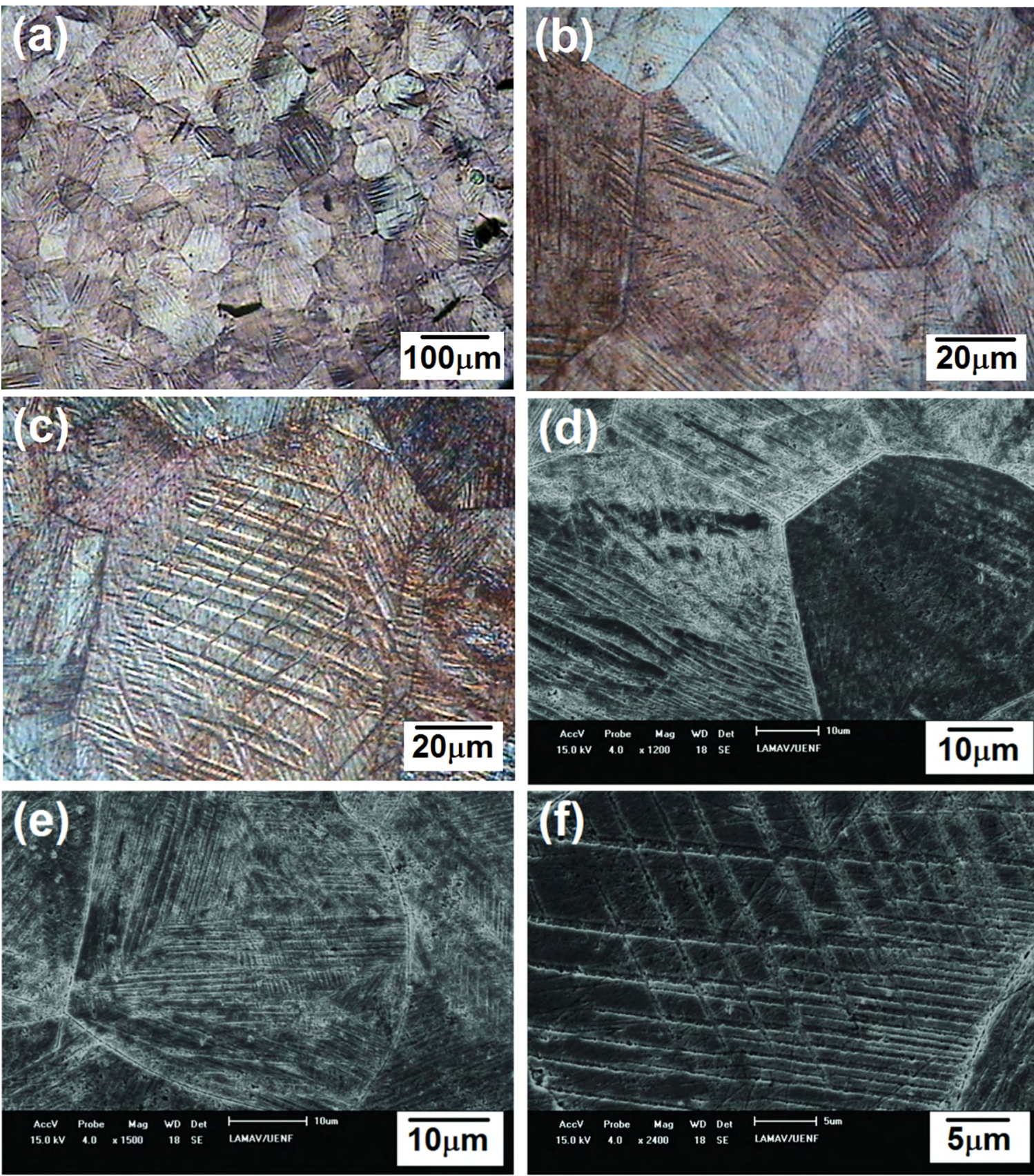

Figure 8. Microstructure of the fractured alloy, analyzed on its bigger face: (a) OM, chemical etching, polarized light, 100x; (b,c) OM, attack, differential interference contrast, 1.000x; (d,e,f) SEM, secondary electrons, 1.200x, 1.500x and 2.400x.

grains. This typical range of electrical resistivities, 10-14 $\mu \Omega \mathrm{cm}$, was previously reported for the CuAlNi alloys ${ }^{56}$.

The X-ray diffraction analysis of the as-cast and fractured alloy, shown in Figure 10, revealed the presence of the martensitic $\beta_{1}^{\prime}$ and $\gamma^{\prime}$, phases as well as the intermediate martensitic $\mathrm{R}$ phase and the high temperature stable $\beta$, phase. According to the relationships between the intensities of the diffracted peaks, the $\beta_{1}^{\prime}$ and $\gamma_{1}^{\prime}$ phases prevail over the $\beta_{1}$ and R phases. However, the applied stress causes the volume fraction of the $\beta_{1}$ phase to decrease by increasing the fraction of $\beta^{\prime}$, and $\mathrm{R}$ due to the occurrence of $\beta_{1} \leftrightarrow \mathrm{R}$ martensitic transformations. The presence of these metastable phases can be assigned to the rapid solidification of the small mass of liquid metal injected in a metallic chill (moderate quenching). Despite the phase transformations observed from the XRD patterns, the main difference in the microstructure of the alloy after the compression test is the presence deformation bands, that grow as the deformation proceeds at high stress levels, and indicate permanent deformation of the alloy ${ }^{67}$. 


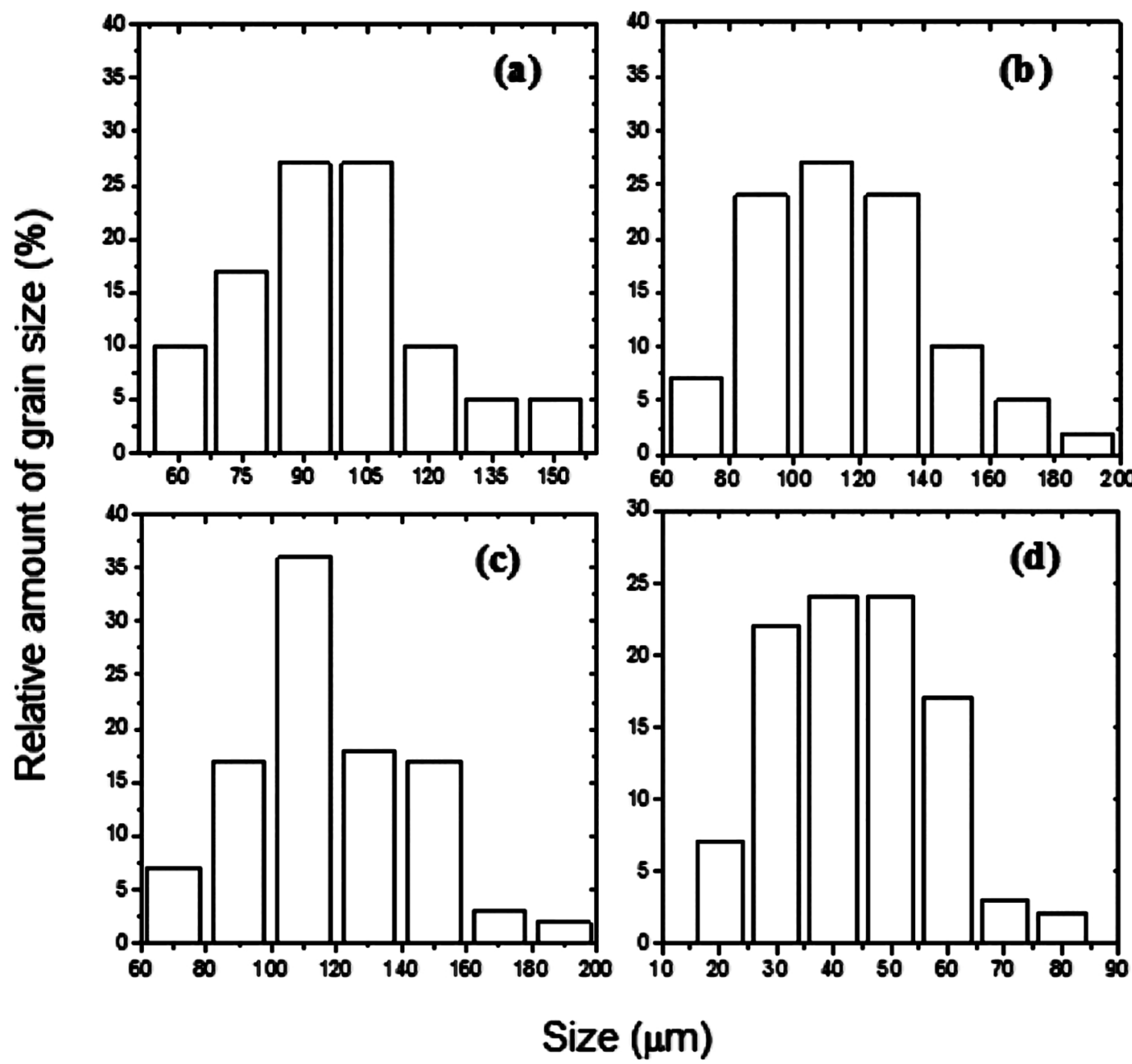

Figure 9. Grain size distribution histograms: as-cast alloy, regions (a) 1; (b) 2; (c) 3; and fractured alloy, (d) bigger face.

Table 4. Grain size variation $\left(\mathrm{d}_{\min }\right.$ and $\left.\mathrm{d}_{\max }\right)$ and average grain sizes $(\mathrm{d})$.

\begin{tabular}{ccccc}
\hline Alloy & Region & $\begin{array}{c}\mathbf{d}_{\min }(\boldsymbol{\mu m}) \\
(\mathbf{m i n i m u m})\end{array}$ & $\begin{array}{c}\mathbf{d}_{\max }(\boldsymbol{\mu m}) \\
(\text { maximum) }\end{array}$ & $\begin{array}{c}\mathbf{d}(\boldsymbol{\mu m}) \\
(\text { average })\end{array}$ \\
\hline \multirow{3}{*}{ As-cast } & 1 & 58 & 154 & $102 \pm 27$ \\
& 2 & 67 & 183 & $115 \pm 30$ \\
Fractured & 3 & 63 & 183 & $120 \pm 34$ \\
\hline
\end{tabular}

Table 5. Average Vickers microhardness (HV).

\begin{tabular}{ccc}
\hline Alloy & Region & HV $\left(\mathbf{k g f} / \mathbf{m m}^{\mathbf{2}}\right)$ \\
\hline \multirow{3}{*}{ As-cast } & 1 & $310 \pm 10$ \\
& 2 & $320 \pm 10$ \\
Fractured & 3 & $330 \pm 13$ \\
\hline
\end{tabular}

Table 6. Average electrical resistivity $(\rho)$

\begin{tabular}{ccc}
\hline Alloy & Region & $\mathbf{r}(\boldsymbol{\mu} \boldsymbol{\Omega} \mathbf{c m})$ \\
\hline \multirow{3}{*}{ As-cast } & 1 & $11.46 \pm 0.12$ \\
& 2 & $11.68 \pm 0.13$ \\
Fractured & 3 & $11.68 \pm 0.13$ \\
& 3 & $19.90 \pm 0.96$
\end{tabular}

It is important to emphasize that the process of fracture in this martensitic alloy is complex and involves, in addition to elastic deformation with little participation of plastic deformation, stress-assisted $\beta_{1} \leftrightarrow \mathrm{R}$ reversible martensitic transformations. Furthermore, as the external compressive stress applied to the alloy generates deformations and structural imperfections that differ from grain to grain, the development of martensitic transformations and the reorientation of 


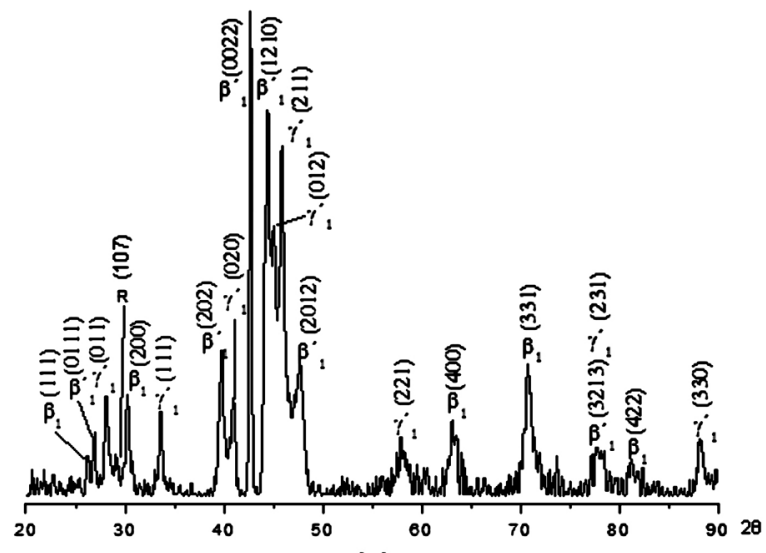

(a)

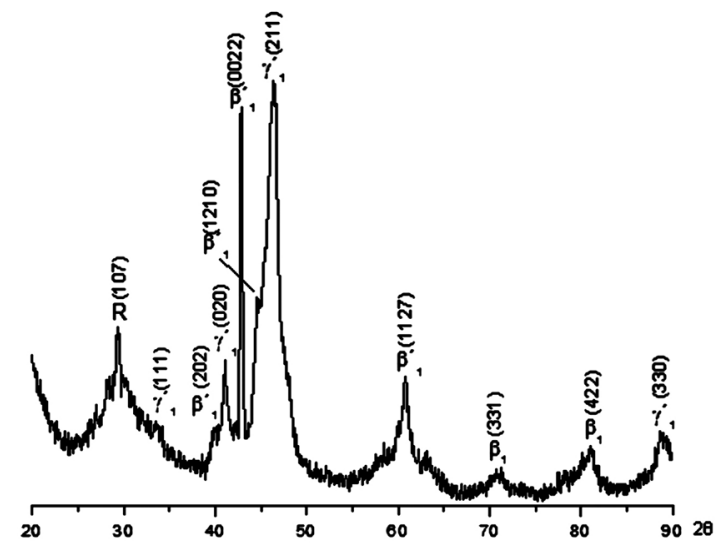

(b)

Figure 10. Diffraction patterns of the (a) as-cast and (b) fractured alloy.

martensites do not occur at the same time and in the same way in all the grains. Therefore, both values of microhardness and resistivity of the deformed alloy might be higher when compared to the initial state, and present a larger deviation from the average, as indicated in Tables 5 and 6.

\section{Conclusions}

- The effect of the compressive deformation on the microstructure and properties of an as-cast $\mathrm{Cu}-14 \mathrm{wt} . \%$ Al-4.0wt.\% Ni plasma melted alloy was investigated and found to present fracture strength superior than that reported for heat treated similar alloy.

- The microstructure of the as-cast alloy is composed of fine grains $(\sim 110 \mu \mathrm{m})$ with martensitic morphology. The martensites $\beta_{1}^{\prime}$ and $\gamma_{1}^{\prime}$ are observed as plates and thin lamellae, parallel and crossed, on a micrometric scale $(\sim 0.5 \mu \mathrm{m})$, with different orientations within the grains. According to the XRD analyzes, there is also a small amount of high temperature $\beta_{1}$ and the intermediary martensitic $\mathrm{R}$ phase.

- The alloy displays high chemical homogeneity, except for porosity. Clear evidence of precipitation or phase transformation was not found at the grain boundaries. This indicates that the as-cast condition could be less susceptible to intergranular embrittlement, as compared to a thermally treated CuAlNi structure.

- The compressive mechanical behavior of the alloy was characterized by the apparent elastic response until fracture at high stress (1260 MPa) and moderate strain $(10.9 \%)$. The ultimate stress is significantly higher than that found by Sari and Kirindi ${ }^{41}$ for a thermally treated CuAlNi alloy with similar composition.

- The plasma melting technique followed by injection molding might be a more satisfactory route to produce high strength and tough polycrystalline $\mathrm{CuAlNi}$ alloys, to be used under compressive loads.

- The fractured surface exhibits "river patterns", mixing intergranular and transgranular types of fracture. The compressive stress applied to the alloy generates deformations and structural imperfections from grain to grain, leading to phase transformations and reorientation of martensites that are not identical to those observed in non-deformed samples.

\section{Acknowledgements}

The authors thank the support to this investigation by the Brazilian agencies: CNPq, CAPES and FAPERJ.

\section{References}

1. Chen CW. Some characteristics of the martensite transformation of Cu-Al-Ni alloys. Journal of Metals. 1957;9:1202-1203.

2. Yang NYC, Laird C, Pope DP. The cyclic stress-strain response of polycrystalline, pseudoelastic Cu-14.5 wt pet Al-3 wt pct Ni alloy. Metallurgical and Materials Transactions: A. 1977;8(6):955-962.

3. Otsuka K, Sakamoto H, Shimizu K. Successive stress-induced martensitic transformations and associated transformation pseudoelasticity in $\mathrm{Cu}-\mathrm{Al}-\mathrm{Ni}$ alloys. Acta Metallurgica. 1979;27(4):585-601.

4. Ritter A, Yang NYC, Pope DP, Laird C. The dislocation and martensite substructures of a fatigued, polycrystalline, pseudoelastic Cu-Al-Ni alloy. Metallurgical Transactions A. 1979;10(6):667-676.

5. Sakamoto H, Shimizu K, Otsuka K. Fatigue Properties Associated with Cyclic $\beta 1$ - $\beta 1$ ' Transformation Pseudoelasticity of $\mathrm{Cu}-\mathrm{Al}$ Ni Alloy Single Crystals. Transactions of the Japan Institute of Metals. 1981;22(8):579-587.

6. Miyasaki S, Otsuka K, Sakamoto H, Shimizu K. The Fracture of Cu-Al-Ni Shape Memory Alloy. Transactions of the Japan Institute of Metals. 1981;22(4):244-252. 
7. Miyazaki S, Kawai T, Otsuka K. On the origin of intergranular fracture in $\beta$ phase shape memory alloys. Scripta Metallurgica. 1982;16(4):431-436.

8. Sakamoto H, Kijima Y, Shimizu K. Fatigue and Fracture Characteristics of Polycrystalline Cu-Al-Ni Shape Memory Alloys. Transactions of the Japan Institute of Metals. 1982;23(10):585594.

9. Miyazaki S, Kawai T, Otsuka K. Study of fracture in CuAlNi shape memory bicrystals. Journal de Physique. 1982;43:C4813-C4-818.

10. Sakamoto H. Fatigue Behavior of Monocrystalline $\mathrm{Cu}-\mathrm{Al}-\mathrm{Ni}$ Shape Memory Alloys under Various Deformation Modes. Transactions of the Japan Institute of Metals. 1983;24(10):665673.

11. Sakamoto H, Shimizu K, Otsuka K. A Detailed Observation on Successive Stress-Induced Martensitic Transformations in $\mathrm{Cu}-\mathrm{Al}-\mathrm{Ni}$ Alloy Single Crystals above $\mathrm{A}_{\mathrm{f}}$ Transaction of the Japan Institute of Metals. 1985;26(9):638-645.

12. Sakamoto H, Shimizu K. Experimental Investigation on Cyclic Deformation and Fatigue Behavior of Polycrystalline Cu-AlNi Shape Memory Alloys above $\mathrm{M}_{\mathrm{s}}$ Transactions of the Japan Institute of Metals. 1986;27(8):592-600.

13. Sakamoto H, Shimizu K. Analytical Investigation on Cyclic Deformation and Fatigue Behavior of Polycrystalline $\mathrm{Cu}-\mathrm{Al}$ Ni Shape Memory Alloys above $\mathrm{M}_{\mathrm{s}}$ Transactions of the Japan Institute of Metals. 1986;27(8):601-607.

14. Husain SW, Clapp PC. The effect of nickel content on the fracture behavior of $\mathrm{Cu}-\mathrm{Al}-\mathrm{Ni} \beta$-phase alloys. Journal of Materials Science. 1987;22(2):509-516.

15. Husain SW, Clapp PC. The granular embrittlement of Cu-Al-Ni $\beta$-phase alloys. Journal of Materials Science. 1987;22(7):23512356.

16. Agafonov V, Naudot $\mathrm{P}$, Dubertret $\mathrm{A}$, Dubois B. Influence of the aluminum content on the appearance and stability of martensites in the Cu-Al-Ni system. Scripta Metallurgica. 1988;22(4):489494.

17. Delaey L, Chandrasekaran L. Comments on "New description of long period stacking order structures of martensites in $\beta$-phase alloys" by K.Otsuka, T.Ohba, M.Tokonami and C.M.Wayman. Scripta Metallurgica et Materialia. 1994;30(12):1605-1610.

18. Shield TW. Orientation dependence of the pseudoelastic behavior of single crystals of Cu-Al-Ni in tension. Journal of Mechanics and Physics of Solids. 1995;43(6):869-895.

19. Novák V, Malimánek J, Zárubová N. Martensitic transformations in single crystals of Cu-Al-Ni induced by tensile stress. Materials Science and Engineering: A. 1995;191(1-2):193-201.

20. Novák V, Šittner P, Zárubová N. Anisotropy of transformation characteristics of $\mathrm{Cu}$-base shape memory alloys. Materials Science and Engineering: A. 1997;234-236:414-417.

21. Recarte V, Pérez-Sáez RB, Bocanegra EH, Nó ML, San Juan J. Dependence of the martensitic transformation characteristics on concentration in $\mathrm{Cu}-\mathrm{Al}-\mathrm{Ni}$ shape memory alloys. Materials Science and Engineering: A. 1999;273-275:380-384.
22. Morawiec H, Lelątko J, Stróż D, Gigla M. Structure and properties of melt-spun Cu-Al-Ni shape memory alloys. Materials Science and Engineering: A. 1999;273-275:708-712.

23. Brinson LC, Schmidt I, Lammering R. Micro and Macromechanical Investigations of CuAlNi Single Crystal and CuAlMnZn Polycrystalline Shape Memory Alloys. Journal of Intelligent Materials Systems and Structures. 2002;13(12):761-772.

24. Vasko GM, Leo PH, Shield TW. Prediction and observation of crack tip microstructure in shape memory CuAlNi single crystals. Journal of the Mechanics and Physics of Solids. 2002;50(9):1843-1867.

25. Tadaki T. Cu-Based shape memory alloys. In: Otsuka K, Wayman CM, eds. Shape Memory Materials. Cambridge: Cambridge University Press; 1998. p. 97-116.

26. Pérez-Ladazábal JI, Recarte V, Pérez-Sáez RB, Nó ML, Campo J, San Juan J. Determination of the next-nearest neighbor order in $\beta$ phase in $\mathrm{Cu}-\mathrm{Al}-\mathrm{Ni}$ shape memory alloys. Applied Physics Letters. 2002;81(10):1794-1796.

27. Gastien R, Corbellani CE, Álvarez Villar HN, Sade M, Lovey FC. Pseudoelastic cycling in Cu-14.3Al-4.1 (wt.\%) single crystals. Materials Science and Engineering: A. 2003;349(12):191-196

28. Loughran GM, Shield TW, Leo PH. Fracture of shape memory CuAlNi single crystals. International Journal of Solids and Structures. 2003;40(2):271-294.

29. Font J, Cesari E, Muntasell, Pons J. Thermomechanical cycling in $\mathrm{Cu}-\mathrm{Al}$-Ni based melt-spun shape-memory ribbons. Materials Science and Engineering: A. 2003;354(1-2):207-211.

30. Dagdelen F, Gokhan T, Aydogdu A, Aydogdu Y, Adigüzel O. Effects of thermal treatments on transformation behavior in shape memory Cu-Al-Ni alloys. Materials Letters. 2003;57(56):1079-1085.

31. Lojen G, Anžel I, Kneissl A, Križman A, Unterweger E, Kosec B, et al. Microstructure of rapidly solidified $\mathrm{Cu}-\mathrm{Al}-\mathrm{Ni}$ shape memory alloy ribbons. Journal of Materials Processing Technology. 2005;162-163:220-229.

32. Gastien R, Corbellani CE, Sade M, Lovey FC. Thermal and pseudoelastic cycling in $\mathrm{Cu}-14.1 \mathrm{Al}-4.2 \mathrm{Ni}(\mathrm{wt} \%)$ single crystal. Acta Materialia. 2005;53(6):1685-1691.

33. Tatar $\mathrm{C}$, Zengin $\mathrm{R}$. The effects of $\gamma$-irradiation on some physical properties of $\mathrm{Cu}-13.5 \mathrm{wt} . \% \mathrm{Al}-4 \mathrm{wt} . \% \mathrm{Ni}$ shape memory alloy. Materials Letters. 2005;59(26):3304-3307.

34. Sari U, Aksoy I. Electron microscopy study of $2 \mathrm{H}$ and $18 \mathrm{R}$ martensites in Cu-11.92 wt.\% Al-3.78 wt.\% Ni shape memory alloy. Journal of Alloys and Compounds. 2006;417(1-2):138142.

35. Picornell C, L'vov VA, Pons J, Cesari E. Experimental and theoretical study of mechanical stabilization of martensite in $\mathrm{Cu}-\mathrm{Al}-\mathrm{Ni}$ single crystals. Materials Science and Engineering: A. 2006;438-440:730-733.

36. Gastien R, Corbellani CE, Sade M, Lovey FC. A $\sigma-\mathrm{T}$ diagram analysis regarding the $\gamma^{\prime}$ inhibition in $\beta \leftrightarrow \beta^{\prime}+\gamma^{\prime}$ cycling in CuAlNi single crystals. Scripta Materialia. 2006;54(8):14511455. 
37. Martynov V, Bokaie MD, Johnson AD, Grey GR. Superelastic and shape memory single Crystal Cu-Al-Ni: Fabrication and Applications. In: SMST-2006: Proceedings of the International Conference on Shape Memory and Superelastic Technologies; 2006 May 7; Pacific Grove, USA.

38. Suresh N, Ramamurty U. Effect of aging on mechanical behavior of single crystal $\mathrm{Cu}-\mathrm{Al}-\mathrm{Ni}$ shape memory alloys. Materials Science and Engineering: A. 2007;454-455:492-499.

39. Matlakhova LA, Pereira EC, Matlakhov AN, Monteiro SN, Toledo R. Mechanical behavior and fracture characterization of a monocrystalline $\mathrm{Cu}-\mathrm{Al}-\mathrm{Ni}$ subjected to thermal cycling treatments under load. Materials Characterization. 2008;59(11):1630-1637.

40. Gastien R, Sade M, Lovey FC. The inhibition of $\gamma^{\prime}$ martensite in $\beta \leftrightarrow \beta^{\prime}+\gamma^{\prime}$ cycling in Cu-Al-Ni single crystals. Materials Science and Engineering: A. 2008;481-482:518-521.

41. Sari U, Kirindi T. Effects of deformation on microstructure and mechanical properties of a $\mathrm{Cu}-\mathrm{Al}-\mathrm{Ni}$ shape memory alloy. Materials Characterization. 2008;59(7):920-929.

42. Gastien R, Sade M, Lovey FC. Interaction between martensitic structure and defects in $\beta \leftrightarrow \beta^{\prime}+\gamma^{\prime}$ cycling in CuAlNi single crystals. Model for the inhibition of $\gamma^{\prime}$ martensite. Acta Materialia. 2008;56(7):1570-1576.

43. Creuziger A, Crone WC. Grain boundary fracture in CuAlNi shape memory alloys. Materials Science and Engineering: A. 2008;498(1-2):404-411.

44. Matlakhova LA, Pereira EC, Matlakhov AN, Monteiro SN. Structure and properties of a monocrystalline $\mathrm{Cu}-\mathrm{Al}-\mathrm{Ni}$ alloy submitted to thermal cycling under load. In: Chen HR, ed. Shape Memory Alloys: Manufacture, Properties and Applications. New York: Nova Science Publishers; 2010. p. 113-143.

45. Gojić M, Vrsalović L, Kožuh S, Kneissl A, Anžel I, Gudić $\mathrm{S}$, et al. Eletrochemical and microstructural study of Cu-AlNi shape memory alloy. Journal of Alloys and Compounds. 2011;509(41):9782-9790.

46. Yin H, Yan Y, Huo Y, Sun Q. Rate depending damping of single crystal CuAlNi shape memory alloy. Materials Letters. 2013;109:287-290.

47. Cava RD, Bolfarini C, Kiminami CS, Mazzer EM, Botta Filho WJ, Gargarella P, et al. Spray forming of Cu-11.85Al-3.2Ni-3Mn (wt\%) shape memory alloy. Journal of Alloys and Compounds. 2014;615(Suppl 1):S602-S606.

48. Saud SN, Hamzah E, Abubakar T, Bakhsheshi-Rad HR, Zamri M, Tanemura M. Effects of Mn Additions on the Structure, Mechanical Properties, and Corrosion Behavior of $\mathrm{Cu}-\mathrm{Al}-\mathrm{Ni}$ Shape Memory Alloys. Journal of Materials Engineering and Performance. 2014;23(10):3620-3629.

49. Saud SN, Hamzah E, Abubakar T, Ibrahim MK, Bahador A. Effect of a fourth alloying element on the microstructure and mechanical properties of $\mathrm{Cu}-\mathrm{Al}-\mathrm{Ni}$ shape memory alloys. Journal of Materials Research. 2015;30(14):2258-2269.

50. Miyazaki S, Otsuka K. Development of Shape Memory Alloys. ISIJ International. 1989;29(5):353-377.

51. Otsuka K, Wayman CM. Mechanism of shape memory effect and superelasticity. In: Otsuka K, Wayman CM, eds. Shape
Memory Materials. Cambridge: Cambridge University Press; 1998. p. 27-48.

52. Otsuka K, Ren X. Martensitic transformation in nonferrous shape memory alloys. Materials Science and Engineering $A$. 1999;273-275:89-105.

53. Novák V, Šittner P, Vokoun D, Zárubová N. On the anisotropy of martensitic transformations in Cu-based alloys. Materials Science and Engineering: A. 1999;273-275:280-285.

54. Melton KN. General applications of SMA's and smart materials. In: Otsuka K, Wayman CM, eds. Shape Memory Materials. Cambridge: Cambridge University Press; 1998. p. 220-239.

55. Miyasaki S. Medical and dental applications of shape memory alloys. In: Otsuka K, Wayman CM, eds. Shape Memory Materials. Cambridge: Cambridge University Press; 1998. p. 267-281.

56. Huang W. On the selection of shape memory alloy for actuators. Materials \& Design. 2002;23(1):11-19.

57. Lagoudas DC, ed. Shape Memory Alloys Modelling and Engineering Applications. New York: Springer. 2008.

58. Asua E, Feuchtwanger J, Etxebarria V, García-Arribas A. Shape Memory Alloys in Micropositioning Applications. In: Chen HR, ed. Shape Memory Alloys: Manufacture, Properties and Applications. New York: Nova Science Publishers; 2010. p. 441-485.

59. Jani JM, Leary M, Subic A, Gibson MA. A review of shape memory alloy research, applications and opportunities. Materials \& Design (1980-2015). 2014;56:1078-1113.

60. Morris MA. Influence of boron additions on ductility and microstructure of shape memory Cu-Al-Ni alloys. Scripta Metallurgica et Materialia. 1991;25(11):2541-2546.

61. Morris MA. High temperature properties of ductile $\mathrm{Cu}-\mathrm{Al}-\mathrm{Ni}$ shape memory alloys with boron additions. Acta Metallurgica et Materialia. 1992;40(7):1573-1586.

62. Morris MA, Lipe T. Microstructural influence of Mn additions on thermoelastic and pseudoelastic properties of $\mathrm{Cu}-\mathrm{Al}-\mathrm{Ni}$ alloys. Acta Metallurgica et Materialia. 1994;42(5):1583-1594.

63. Pelosin V, Rivière A. Structural and mechanical spectroscopy study of the $\beta_{1}{ }^{\prime}$ martensite decomposition in $\mathrm{Cu}-12 \% \mathrm{Al}-3 \%$ $\mathrm{Ni}(\mathrm{wt} \%)$ alloy. Journal of Alloys and Compounds. 1998;268(12):166-172.

64. Gama JLL, Dantas CC, Quadros NF, Ferreira RAS, Yadava YP. Microstructure-mechanical property relationship to copper alloys with shape memory during thermomechanical treatments. Metallurgical and Materials Transactions A. 2006;37(1):77-87.

65. Mukunthan K, Brown LC. Preparation and properties of fine grain $\beta$-CuAlNi strain-memory alloys. Metallurgical Transaction A. 1987;19(12):2921-2929.

66. Lojen G, Gojić M, Anžel I. Continuously cast Cu-Al-Ni shape memory alloy - Properties in as-cast condition. Journal of Alloys and Compounds. 2013;580:497-505.

67. Wayman CM. Deformation, Mechanisms and Other Characteristics of Shape Memory Alloys. In: Perkins J, ed. Shape Memory Effects in Alloys. $1^{\text {st }}$ ed. New York: Plenum Press; 1975. p. $1-27$ 